\title{
Quality assessment of clinical practice guidelines for chronic kidney disease: a systematic review
}

Jorge Coronado Daza ${ }^{1,2^{*}}$ D, Robin W. M. Vernooij ${ }^{3,4 \dagger}$, Karla Salas ${ }^{5 \dagger}$, Dimelza Osorio ${ }^{6 \dagger}$ and Gerard Urrútia Cuchi ${ }^{3,4,7 \dagger}$

\begin{abstract}
Background: Chronic kidney disease (CKD) is a worldwide public health problem. Clinical practice guidelines (CPGs) are being developed and implemented in order to improve clinical practice related to the detection and treatment of CKD. The objective of our study was to evaluate the quality of CPGs regarding the CKD and to examine whether there are factors which influence their quality.

Methods: A systematic search was conducted to identify all CPGs regarding the early diagnosis and treatment of CKD. The CPGs quality were evaluated by three reviewers using the AGREE II instrument to decide if the guidelines are recommended for their use in clinical practice.

Results: In total, 13 CPGs were identified: five from America, six from Europe, one from Asia, and one from Oceania. Five CPGs were recommended for their use in clinical practice; since all their domains achieved the medium or high category. Furthermore, six CPGs were recommended with modifications, as the stakeholders' involvement, applicability, and editorial independence domains were evaluated as low category. These domains, as well as the rigor of the development domain, reached the very low category in those CPGs that were not recommended for its use in clinical practice. In all CPGs, the domains with the lowest average were the stakeholder involvement and the applicability. When comparing the domains of the CPGs according to the origin, type of developer group, the checklist used during the development and the publication period, a significantly higher average in the domain stakeholder involvement was found in the CPGs from Asia and Oceania compared to the ones in Latin America. Additionally, a significantly higher average in the applicability domain was found in the CPGs developed by CPGs developer organizations compared to those developed by medical societies.
\end{abstract}

Conclusions: In total, $85 \%$ of the CPGs regarding CKD were recommended or recommended with modifications. The stakeholder involvement and applicability domains are assessed in the low category, which might affect the CPGs implementation. In order to save resources in low- and middle-income countries, an adaptation of the recommended CPGs should be considered.

Keywords: Chronic kidney disease, Clinical practice guidelines, Quality assessment, Early diagnosis

\footnotetext{
* Correspondence: jocodada@yahoo.es

${ }^{\dagger}$ Robin W. M. Vernooij, Karla Salas, Dimelza Osorio and Gerard Urrútia Cuchí

contributed equally to this work.

${ }^{1}$ Facultad de Medicina, Universidad de Cartagena, Cartagena 130014,

Colombia

${ }^{2}$ Nefrologia y Diálisis SAS, Cartagena 130001, Colombia

Full list of author information is available at the end of the article
}

(c) The Author(s). 2019 Open Access This article is distributed under the terms of the Creative Commons Attribution 4.0 International License (http://creativecommons.org/licenses/by/4.0/), which permits unrestricted use, distribution, and reproduction in any medium, provided you give appropriate credit to the original author(s) and the source, provide a link to the Creative Commons license, and indicate if changes were made. The Creative Commons Public Domain Dedication waiver (http://creativecommons.org/publicdomain/zero/1.0/) applies to the data made available in this article, unless otherwise stated. 


\section{Background}

Chronic kidney disease (CKD) is considered since 2005 a worldwide public health problem. Furthermore, since 2007, all countries have been urged to adopt actions for the control of CKD [1, 2]. The interest in establishing CKD as a public health issue was crucial to establish control measures and stopping the increase of CKD incidence. However, to date, there is no evidence stating that the use of control strategies has contributed to a decrease in the incidence of CKD. For instance, in the United States of America (USA), the incidence of CKD increased from 353 per million population (pmp) in 2005 to $370 \mathrm{pmp}$ in 2014 [3].

One strategy to tackle the problem has been the development of CPGs for use of the stakeholders (physicians, patients, educators, health care providers, and government regulatory agencies). The main objectives of CPGs are the identification of the population at risk of CKD, early detection, and strategies to avoid the progression of the disease. To achieve these objectives, appropriate stakeholders must get involved in the development process of CPGs, as recommended by the AGREE (Appraisal of Guidelines for Research \& Evaluation) and its updated version, AGREE II $[4,5]$. The AGREE II instrument was also created to help achieving adequate reporting of the development process and presentation of CPGs.

In two recent systematic reviews the quality of CPGs addressing CKD has been analysed. The AGREE II domains with the lowest scores are stakeholder's involvement and applicability [6, 7]. This is similar to CPGs evaluations in other diseases [8-10].

In this study, we present a quality assessment of CPGs regarding the early detection and management of CKD. Additionally, we evaluated whether there was a difference in the quality according to the region where the CPGs were developed, type of developer organization, self-assessment process in its development, and publication period.

\section{Methods}

We included national and regional CPGs for the early detection and management of CKD. We included CPGs which included: 1) recommendations based on systematic evidence synthesis; 2) employing a grading system to rate the quality of evidence, 3) published in English, Spanish or languages that were feasible to translate for the authors; and 4) published between 2008 and 2016.

\section{CPGs identification}

A systematic search was conducted in the main databases of organisations that develop or compile CPGs including: the Turning Research Into Practice (TRIP) database, National Guideline Clearinghouse (via https:// www.ahrq.gov/topics/national-guideline-clearinghousengc.html), National Institute for Health and Care Excellence (NICE), Scottish Intercollegiate Guidelines Network (SIGN), Guidelines International Network (G-I-N), and the National Health System library of Spain. An additional search was conducted in the international nephrology societies or associations webpages of each country or region. Additionally, a systematic search was performed in MEDLINE and EMBASE, investigating the medical terms headers related to CKD, applying CPG filters.

\section{Clinical practice guidelines assessment}

Three authors independently (JC, RV, KS) assessed the quality of each CPG, under the guidance of an expert in Investigation Methodology (DO). The AGREE II instrument [5], which consists of 23 items organized in six domains, followed by 2 items of global score (overall assessment), was used. Each domain embraces a unique dimension in the CPG quality: scope and purpose, stakeholder(s) involvement, clarity of presentation, rigour of development, applicability, and editorial independence. The overall assessment includes a score for the general quality of the CPG and an assessment whether it is recommended for use in clinical practice. Each item was assessed using a 7-point scale (from 1 "strongly disagree" to 7 "strongly agree"), even if it was not applicable. The domain scores was expressed as a percentage over the highest possible score using the following formula:

Obtained score - Minimum possible score

Maximum possible score - Minimum possible score

The final score is the sum of the total scores assigned to each domain by each reviewer. The maximum possible score is 7 (strongly agree), multiplied by the number of items in the domain and the number of reviewers. The minimum possible score is 1 (strongly disagree) multiplied by the number of items in the domain and the number of reviewers. For the overall assessment, a score from 1 to 7 was consigned, as well as a recommendation regarding the use of the CPG in clinical practice classified as: recommended, recommended with modifications, and not recommended.

\section{Data analysis}

Descriptive statistics were applied to analyse every domain (percentage; mean and standard deviation; median and interquartile range). The mean of the domains score was categorized as high $(\geq 80 \%)$, medium $(60-79 \%)$, low $(40-59 \%)$, or very low $(\leq 40 \%)$. The overall mean of each of the CPGs domains were compared using Student's t-tests for independent samples (the test was two-tailed, 
and statistical significance was considered for $P$-values of less than 0.05), according to: CPG region, developer group, use of a self-assessment instrument, and publication period (2008-2011 versus 2012-2016).

The degree of agreement between reviewers was determined by the measurement of intraclass correlation coefficient (ICC) and its 95\% confidence interval. An ICC of $>0.9$ was considered "very good", between 0.71 and 0.9 "good", between 0.51 and 0.7 "moderate", between 0.31 and 0.5 "fair", and $<0.31$ "poor" or "non-existent".

\section{Results}

The systematic search retrieved 893 records. After deleting duplicates and reviewing titles and abstracts, we identified 24 CPGs that were potentially eligible (Fig. 1). Consequently, after the full-text evaluation, 11 CPGs were excluded because they did not concern national CPGs, did not include recommendations regarding screening or early diagnosis of CKD, or did not present recommendations based on the evidence (Additional file 1). Finally, 11 national CPGs and two regional CPGs were included. The
CPGs included were from Scotland [11], Spain [12], Netherlands [13], Mexico [14], Argentina [15], Chile [16], Malaysia [17], England [18], Italy [19], Sociedad Latinoamericana de Nefrología e Hipertensión (SLANH) [20], Australasia [21], USA [22] and United Kingdom (NICE guideline) [23].

General characteristics of the 13 included CPGs are presented in Table 1. Six CPGs were developed in Europe (46.2\%), four in Latin America (30.7\%), one in Asia (7.7\%), one in Oceania (7.7\%), and one in the USA (7.7\%). Eight CPGs (61.5\%) were published between 2008 and 2011 and five between 2012 and 2016 (38.5\%). Regarding the language, five CPGs were written in Spanish (38.4\%), six in English (46.2\%), one in Italian (7.7\%), and one in Dutch (7.7\%). Eight CPGs (61.5\%) were issued by organizations that develop CPGs, three (23.1\%) by medical societies, and two (15.4\%) by medical societies with an organization dedicated to developing CPGs (15.4\%). Concerning the CPG developer panel, 12 (92\%) included nephrologists, four (30.7\%) experts in methodology, and four (30.7\%) the target population. During

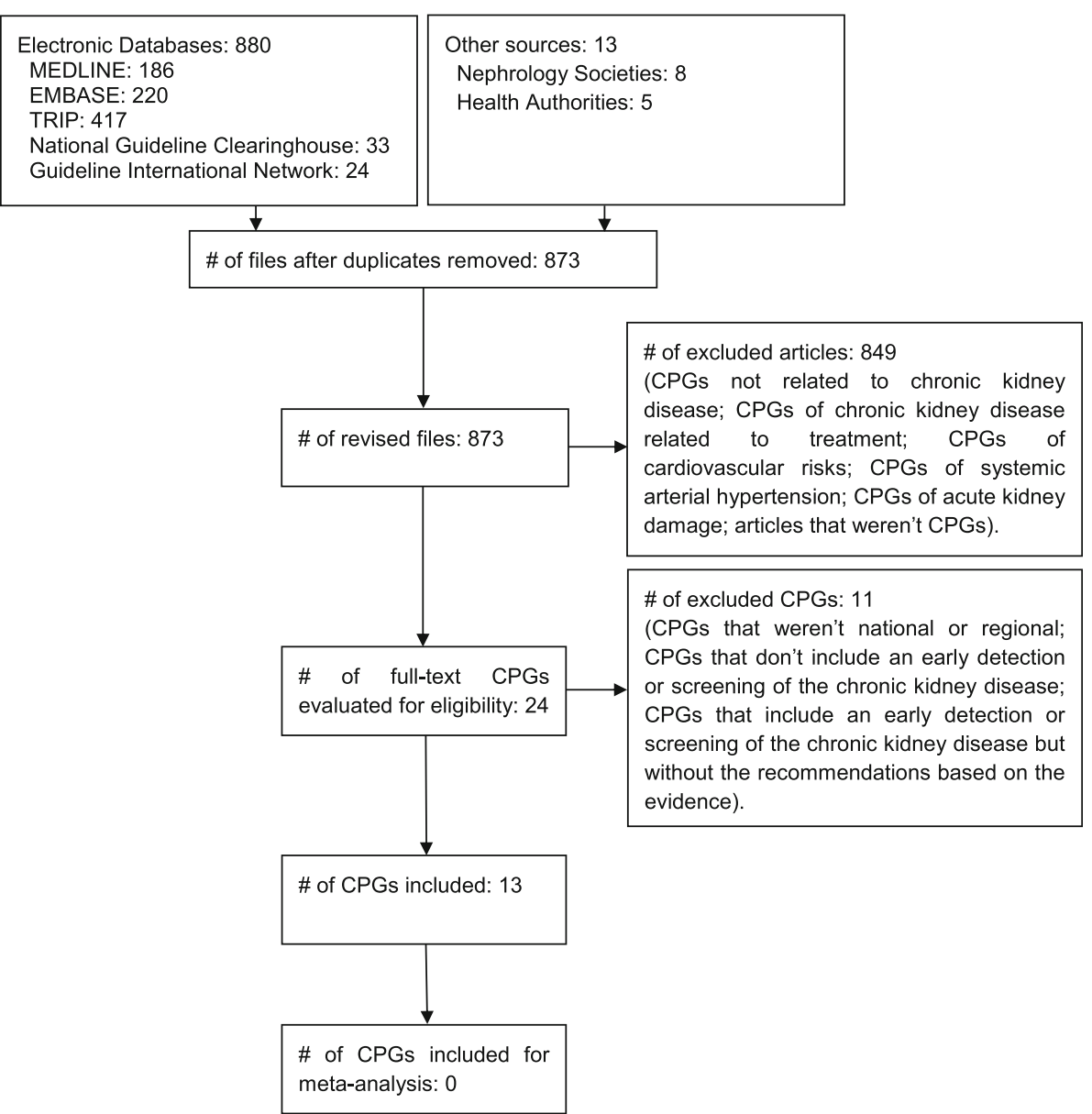

Fig. 1 Flowchart of bibliographical research 


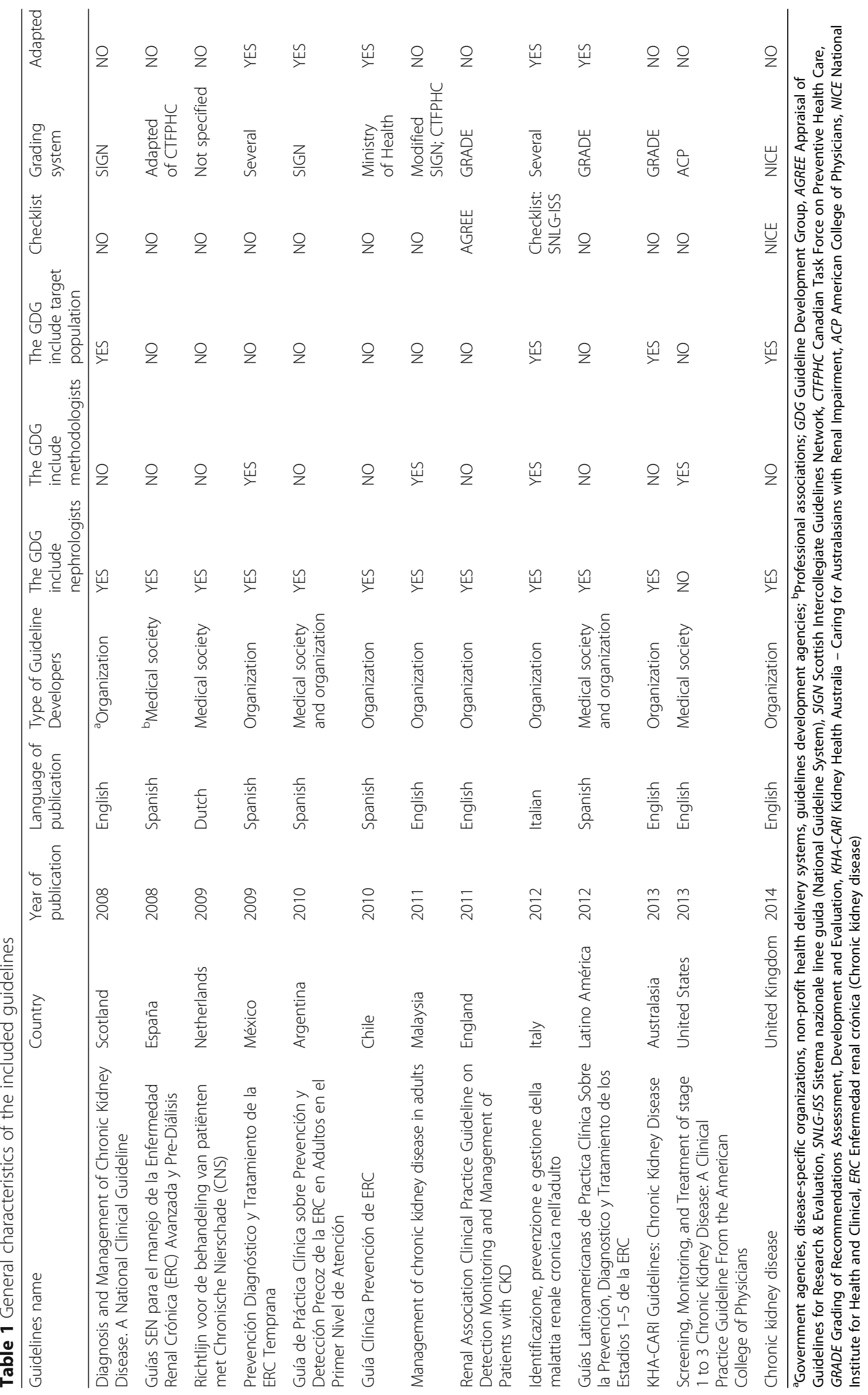


the CPGs development process, only three CPGs (23.1\%) used a checklist to verify if they were fulfilling the requirements that a CPG should have. The system used to classify the quality of evidence and the strength of the recommendations differed among the included CPGs; three (23.1\%) used the GRADE (Grading of Recommendations Assessment, Development and Evaluation) system, three used the CPG developers' own system (23.1\%), three used mixed systems (23.1\%), two (15.4\%) the SIGN (Scottish Intercollegiate Guidelines Network) tool, one (7.7\%) used CTFPHC (Canadian Task Force on Preventive Health Care) system, and one did not specify the used system (7.7\%). Five CPGs (38.5\%) were adapted from international CPGs: all four Latin America and one European.

\section{CPGs quality general assessment}

The degree of agreement between the three reviewers was good, with an ICC of 0.88 (95\% CI: 0.67-0.96) for the overall score. The CPG quality score varied from 3 to 7 and the reviewers recommended five CPGs (38.5\%; CPG scores between 5 and 7: Scotland, Malaysia, Australasia, USA and United Kingdom). Six CPGs were recommended with modification (46.1\%; CPG scores between 4 to 5 : Mexico, Argentina, Chile, England, Italy and SLANH), and two CPGs were not recommended (15.4\%; CPG scores between 3 to 4: Spain and Netherlands). The average score of each domain of all included CPGs and their respective recommendation can be observed in Table 2, and Fig. 2.

\section{Domain 1: scope and purpose}

This domain refers to the CPG general objective, the specific health aspects, and the population to whom this CPG is intended (items $1-3$ ). The overall average score was $80.1 \%$ (median $=88.9 \%$; interquartile range (IQR), 50 to 98.2\%). Furthermore, $61.5 \%$ of the included CPGs had an average score of $80 \%$ or higher, which is considered high category. The average score of the recommended CPGs was $93,77.5 \%$ for the CPGs recommended with modifications, and $62 \%$ for the CPGs that were not recommended.

\section{Domain 2: stakeholder involvement}

This domain refers to the degree to which stakeholders have developed the CPG and the representation of the points of view of the intended users (items 4-6). The overall average was $58.2 \%$ (median $=59.3 \%$; IQR, 27.8 to 94.4\%). Furthermore, $15.3 \%$ of the CPGs were evaluated as high category, $15.3 \%$ as medium category, and $69.4 \%$ as low or very low category. The CPGs that were recommended had an average score of $74.4 \%$, the CPGs recommended with modifications scored $53.4 \%$, and the CPGs that were not recommended scored $39.8 \%$.

\section{Domain 3: rigour of development}

The rigour of development domain considers the process used to gather and synthesize the evidence, the methods to formulate the recommendations, and the updating process (items $7-14$ ). The overall average score was $64.9 \%$ (median $=68.4 \%$; IQR, 22.9 to $93.1 \%$ ). Furthermore, $38.4 \%$ of the CPGs were considered within the high category, $23 \%$ within the medium category, and $38.6 \%$ within the low or very low category. The average score of the CPGs that were recommended for use in clinical practice was $85.3 \%$, for CPGs recommended with modifications was $61.7 \%$, and for those not recommended $31.9 \%$.

\section{Domain 4: clarity of presentation}

The clarity of presentation domain refers to the language, structure, and the CPGs format (items 15-17). The overall average was $88.9 \%$ (median $=92.59 \%$; IQR, 62.96 to $96.3 \%$ ). In total, $92.3 \%$ of the CPGs were considered within the high category. The average score of the CPGs recommended for use in clinical practice was $93.3 \%$, for those recommended with modifications $91 \%$, and for those not recommended $72.2 \%$.

\section{Domain 5: applicability}

This domain is related to the barriers and facilitators to its implementation, strategies to improve uptake, and resource implications when applying the CPGs (items $18-21$ ). The overall average score was $47.9 \%$ (median = 43.75; IQR, 2.78 to $87.5 \%$ ). In total, $23 \%$ of the CPGs were assessed as the high category, $15.3 \%$ as the medium category, and $61.7 \%$ as the low or very low category. The average score of the recommended CPGs was $69.4 \%$, for those recommended with modifications $45.8 \%$, and for those not recommended $6.9 \%$.

\section{Domain 6: editorial independence}

Finally, the editorial independence domain refers to the conflicts of interest of the panel members and the role of the funding body (items 22-23). The overall average was $62.7 \%$ (median $=59.72 \%$; IQR, 19.44 to $94.44 \%$ ). In total, $23 \%$ of the CPGs were in the high category, $30.7 \%$ in the medium category, and $46.3 \%$ in the low or very low category. The average score of the recommended CPGs was $85 \%$, those recommended with modifications scored $55.6 \%$, and those not recommended scored $36.1 \%$.

\section{CPGs assessment according to recommendation}

When comparing the AGREE II domains between the recommended CPGs and the CPGs recommended with modifications, we found a significant difference in the stakeholder involvement $(74.4 \pm 14.3$ vs. $53.4 \pm 8.2$ respectively; $p=0.013)$, rigor of development (85.3 \pm 5 


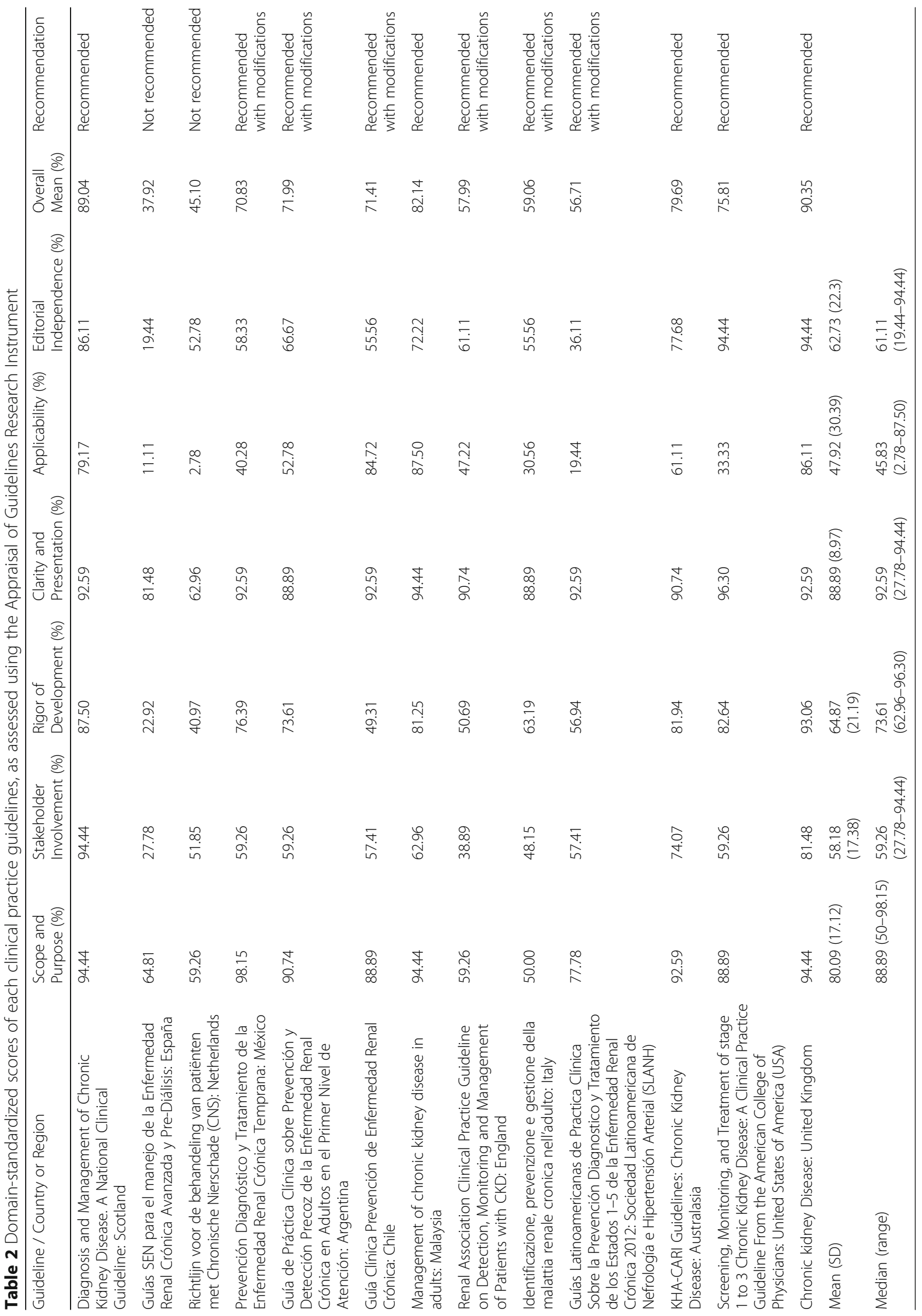




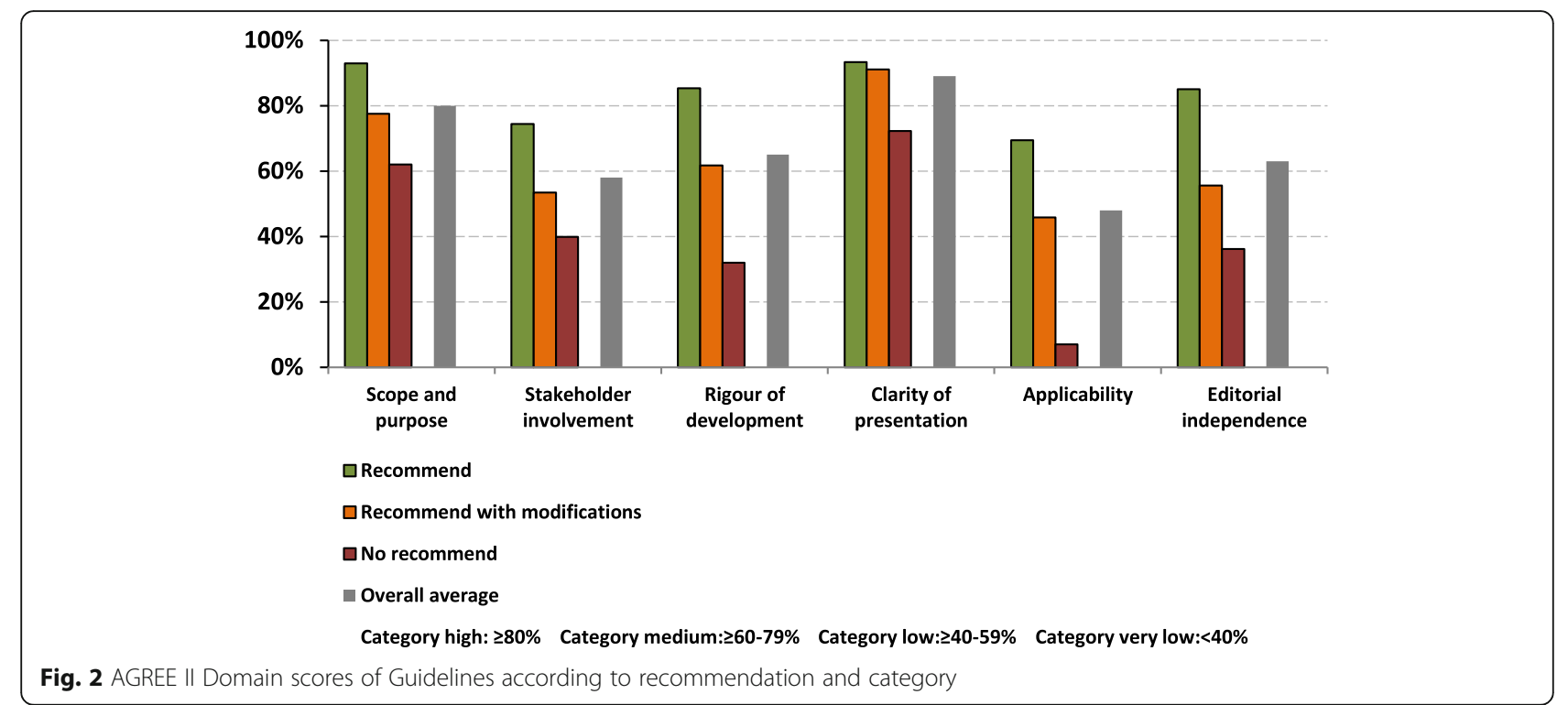

vs. $61.7 \pm 11.5$ respectively; $p=0.002)$, and the editorial independence domains $(85.0 \pm 10$ vs. $55.6 \pm 10.4$ respectively; $p=0.001$ ). Between the recommended CPGs and the CPGs that were not recommended there was a statistically significant difference in all domains. A statistically significant difference was found between the CPGs recommended with modifications compared to those not recommended in the rigor of development $(61.7 \pm 11.5$ vs.
$31.9 \pm 12.3$ respectively; $p=0.02)$ and clarity of presentation domains $(91.1 \pm 1.8$ vs. $72.2 \pm 13.1$ respectively; $p=0.006)$.

\section{CPGs assessment according to subgroups}

The overall averages and the domain score of the included CGPs according to each subgroup are described as follows and resumed in Table 3.

Table 3 AGREE II domain scores of Guidelines according to different subgroups

\begin{tabular}{|c|c|c|c|c|c|c|c|}
\hline Subgroup & $\begin{array}{l}\text { Scope and } \\
\text { Purpose } \\
\text { Mean } \pm \text { SD }\end{array}$ & $\begin{array}{l}\text { Stakeholder } \\
\text { Involvement } \\
\text { Mean } \pm \text { SD }\end{array}$ & $\begin{array}{l}\text { Rigor of } \\
\text { Development } \\
\text { Mean } \pm S D\end{array}$ & $\begin{array}{l}\text { Clarity and } \\
\text { Presentation } \\
\text { Mean } \pm \text { SD }\end{array}$ & $\begin{array}{l}\text { Applicability } \\
\text { Mean } \pm \text { SD }\end{array}$ & $\begin{array}{l}\text { Editorial } \\
\text { Independence } \\
\text { Mean } \pm \text { SD }\end{array}$ & $\begin{array}{l}\text { Overall } \\
\text { Mean } \pm \text { SD }\end{array}$ \\
\hline \multicolumn{8}{|l|}{ Region } \\
\hline Latinoamérica & $88.89 \pm 8.42$ & $58.34 \pm 1.07$ & $64.06 \pm 13.06$ & $91.67 \pm 1.85$ & $49.31 \pm 27.32$ & $54.17 \pm 12.93$ & $67.74 \pm 7.36$ \\
\hline Europe & $70.37 \pm 19.24$ & $57.10 \pm 25.64$ & $59.72 \pm 27.14$ & $84.88 \pm 11.5$ & $42.83 \pm 34.57$ & $61.57 \pm 26.73$ & $62.74 \pm 22.13$ \\
\hline Asia+Oceania & $93.52 \pm 1.31$ & $68.52 \pm 7.85$ & $81.60 \pm 0.49$ & $92.59 \pm 2.62$ & $74.31 \pm 18.66$ & $74.95 \pm 3.86$ & $80.91 \pm 1.73$ \\
\hline \multicolumn{8}{|l|}{ Developers } \\
\hline Medical societies & $70.99 \pm 15.75$ & $46.30 \pm 16.46$ & $48.84 \pm 30.63$ & $80.25 \pm 16.7$ & $15.74 \pm 15.8$ & $55.56 \pm 37.58$ & $52.94 \pm 20.12$ \\
\hline Organization & $84.03 \pm 18.49$ & $64.58 \pm 18.05$ & $72.92 \pm 16.59$ & $91.90 \pm 1.7$ & $64.58 \pm 22.89$ & $70.13 \pm 14.9$ & $74.69 \pm 13.00$ \\
\hline Medical societies and organization & $84.26 \pm 9.17$ & $58.33 \pm 1.31$ & $65.28 \pm 11.79$ & $90.74 \pm 2.62$ & $36.11 \pm 23.57$ & $51.39 \pm 21.61$ & $64.35 \pm 10.80$ \\
\hline \multicolumn{8}{|l|}{ Self-assessment } \\
\hline Yes & $67.90 \pm 23.45$ & $56.17 \pm 22.4$ & $68.98 \pm 21.77$ & $90.74 \pm 1.85$ & $54.63 \pm 28.51$ & $70.37 \pm 21.03$ & $68.13 \pm 19.27$ \\
\hline No & $85.00 \pm 13.31$ & $60.37 \pm 16.71$ & $65.35 \pm 21.68$ & $88.52 \pm 9.83$ & $47.22 \pm 30.85$ & $61.93 \pm 22.67$ & $68.07 \pm 16.44$ \\
\hline \multicolumn{8}{|l|}{ Year of publication } \\
\hline $2008-2011$ & $81.25 \pm 16.98$ & $56.48 \pm 19.47$ & $60.33 \pm 22.67$ & $87.04 \pm 10.52$ & $50.70 \pm 32.32$ & $59.03 \pm 19.23$ & $65.80 \pm 17.60$ \\
\hline $2012-2016$ & $80.74 \pm 18.36$ & $64.07 \pm 13.46$ & $75.55 \pm 14.97$ & $92.22 \pm 2.75$ & $46.11 \pm 27.12$ & $71.65 \pm 25.48$ & $71.72 \pm 14.98$ \\
\hline \multicolumn{8}{|l|}{ Recommendation } \\
\hline Recommended & $92.96 \pm 2.41$ & $74.44 \pm 14.25$ & $85.28 \pm 4.99$ & $93.33 \pm 2.11$ & $69.44 \pm 22.76$ & $84.98 \pm 9.96$ & $83.41 \pm 6.19$ \\
\hline Recommended with modifications & $77.47 \pm 19.08$ & $53.40 \pm 8.23$ & $61.69 \pm 11.46$ & $91.05 \pm 1.82$ & $45.83 \pm 22.46$ & $55.56 \pm 10.39$ & $64.17 \pm 7.97$ \\
\hline Not recommended & $62,04 \pm 3.93$ & $39,81 \pm 17.02$ & $31,94 \pm 12.77$ & $72,22 \pm 13.09$ & $6,94 \pm 5.89$ & $36,11 \pm 23.57$ & $41.51 \pm 5.07$ \\
\hline
\end{tabular}




\section{CPGs assessment according to the region}

Out of the six CPGs developed in Europe, two were recommended (Scotland and United Kingdom), two recommended with modifications (England and Italy), and two were not recommended (Spain and Netherlands). The four Latin American CPGs (Mexico, Argentina, Chile and SLANH) were all recommended with modifications. The CPGs from Asia (Malaysia), Oceania (Australasia) and USA were all recommended. When comparing the domain scores of the CPGs from Asia and Oceania with the Latin American CPGs, we found a statistically significant difference in the stakeholder involvement domain ( $68.5 \pm 7.9$ vs. $58.3 \pm 1$ respectively; $p=0.04)$, however, when comparing with the European CPGs, no difference was found $(68.5 \pm 7.9$ vs. $57.1 \pm 25.6$ respectively; $p=0.57$ ).

In Latin American CPGs, the domains with the lowest scores were stakeholder involvement, applicability, and editorial independence. Similarly, in European CPGs, the domains with the lowest scores were stakeholder involvement and applicability. When comparing Latin American and European CPGs, we found no significant difference in the AGREE II domains.

\section{CPGs assessment according to the types of development groups}

In total, three CPGs were developed by medical societies (Spain, Netherlands and USA), two were developed jointly by medical societies and organizations that develop CPGs (Argentina and SLANH) and the remaining eight CPGs by organizations responsible for developing CPGs.

For the organizations that develop CPGs and medical societies, the domains with the lowest scores were stakeholder involvement and applicability. When comparing these domains between the organizations that develop CPGs and medical societies, no statistically significant difference was found in the stakeholder involvement ( $64.6 \pm 18.1$ vs. $46.3 \pm 16.5$ respectively; $p=$ $0.16)$ domain, however, we found a difference in the applicability domain $(64.58 \pm 22.9$ vs. $15.74 \pm 15.8$ respectively; $p=0.009$ ).

CPGs assessment according to the self-assessment during the process of development

Three CPGs (23\%) used a checklist during the development process to verify if they were fulfilling reporting requirements (England, Italy and United Kingdom). The overall score of the CPGs that self-assessed the fulfillment of the requirements was $68.1 \pm 19.3$ compared to the overall score of $68.1 \pm 16.4$ for the CPGs that did not self-asses their reporting $(p=0.10)$. In both groups, the domains with the lowest scores were stakeholder involvement and applicability with no significant statistical difference between them.

\section{CPGs assessment according to the time period of publication}

For the period between 2008 and 2011, eight CPGs (61.5\%) were published, out of which two were recommended, four were recommended with modifications, and two were not recommended. In the time frame between 2012 and 2016, five CPGs (38.5\%) were published, out of which three were recommended and two were recommended with modifications.

The overall average score of the CPGs published in the period between 2008 and 2011 was $65.8 \pm 17.6$ and for the CPGs published in the period between 2012 and 2016 it was $71.7 \pm 15(p=0.55)$. In both periods, the domains with the lowest scores were stakeholder involvement and applicability with no significant statistical difference between them.

Synthesis of recommendations for chronic kidney disease We identified general recommendations for CKD in the included CPGs: early diagnosis, investigations or diagnostic test, interventions for slowing the progression and criteria for referral to the nephrologist (Table 4). For the early diagnosis of CKD, all CPGs recommended to study CKD in patients with diabetes mellitus and systemic arterial hypertension. Furthermore, the majority of the CPGs stated that patients with cardiovascular diseases, systemic diseases that affect the kidney and family history of end-stage kidney disease must be investigated.

To evaluate the presence of CKD, all CPGs recommended estimating the glomerular filtration with the formulas based in the serum creatinine and to measure the albuminuria. The formula most used to estimate the glomerular filtration is MDRD (Modification of Diet in Renal Disease).

To avoid the progression of CKD, all CPGs recommended stabilizing the arterial pressure and using angiotensin converting enzyme inhibitors or angiotensin II receptors blockers. The majority of the CPGs recommended controlling proteinuria, stabilize weight, avoid smoking, and controlling lipids.

Eleven (85\%) included CPGs reported criteria to obtain a referral to the nephrology department, this concerns especially patients with a low estimated glomerular filtration and proteinuria or albuminuria. The majority of the CPGs (73\%) recommend a referral to a nephrologist when the estimated glomerular filtration is below 30 $\mathrm{mL} / \mathrm{min} / 1.73 \mathrm{~m}^{2}$.

\section{Discussion}

The 13 CPGs focused on the early detection of the CKD and included in this study represent the current scenario worldwide, since we included CPGs published between 2008 and 2016 in different languages, with a geographical variation over all continents. 
Table 4 General guidelines recommendations for chronic kidney disease

\begin{tabular}{|c|c|c|}
\hline & Number & Percen \\
\hline \multicolumn{3}{|l|}{ Screening for Chronic Kidney Disease (CKD) } \\
\hline Diabetes mellitus & 13 & 100 \\
\hline Hypertension & 13 & 100 \\
\hline Cardiovascular disease & 11 & 85 \\
\hline Family history of end-stage kidney disease & 10 & 77 \\
\hline $\begin{array}{l}\text { Multisystem diseases with potential kidney } \\
\text { involvement }\end{array}$ & 8 & 62 \\
\hline Structural renal tract disease & 8 & 62 \\
\hline Chronic use of nephrotoxic drugs & 6 & 46 \\
\hline Proteinuria & 6 & 46 \\
\hline Aged over 60 years & 4 & 31 \\
\hline Isolated Hematuria & 3 & 23 \\
\hline Low socioeconomic status & 3 & 23 \\
\hline Cigarrete smoking & 3 & 23 \\
\hline Obesity & 1 & 8 \\
\hline \multicolumn{3}{|l|}{ Investigations for CKD } \\
\hline $\begin{array}{l}\text { Creatinine-based equations for estimation } \\
\text { renal function }\end{array}$ & 13 & 100 \\
\hline${ }^{\mathrm{a} M D R D}$ & 11 & 85 \\
\hline Cockcroft Gault & 6 & 46 \\
\hline${ }^{\mathrm{b}} \mathrm{CKD}-\mathrm{EPI}$ & 4 & 31 \\
\hline Albuminuria & 13 & 100 \\
\hline Proteinuria & 10 & 77 \\
\hline Hematuria & 5 & 39 \\
\hline Renal ultrasound & 2 & 15 \\
\hline \multicolumn{3}{|c|}{ I nterventions for slowing the rate of progression of CKD } \\
\hline Optimal blood pressure range & 13 & 100 \\
\hline $\begin{array}{l}\text { Use of angiotensin converting enzyme } \\
\text { inhibitors or angiotensin receptor blockers }\end{array}$ & 13 & 100 \\
\hline Optimal proteinuria reduction & 12 & 92 \\
\hline Optimal weight & 12 & 92 \\
\hline Smoking cessation & 12 & 92 \\
\hline Lipid lowering with statin therapy & 12 & 92 \\
\hline Sodium restriction & 10 & 77 \\
\hline Exercise & 10 & 77 \\
\hline Optimal glycemic control & 9 & 69 \\
\hline Patient education & 5 & 39 \\
\hline Moderate intake of alcohol & 4 & 31 \\
\hline \multicolumn{3}{|l|}{ Referral to the nephrologist } \\
\hline Statement of criteria for referral & 11 & 85 \\
\hline $\begin{array}{l}\text { Reduced glomerular filtration rate or } \\
\text { creatinine clearance }\end{array}$ & 11 & 100 \\
\hline$<30 \mathrm{~mL} / \mathrm{min} / 1.73 \mathrm{~m}^{2}$ & 8 & 73 \\
\hline$<60 \mathrm{~mL} / \mathrm{min} / 1.73 \mathrm{~m}^{2}$ & 2 & 18 \\
\hline
\end{tabular}

Table 4 General guidelines recommendations for chronic kidney disease (Continued)

\begin{tabular}{cll}
\hline & Number & Percent \\
\hline$<45 \mathrm{~mL} / \mathrm{min} / 1.73 \mathrm{~m}^{2}$ & 1 & 9 \\
Proteinuria or albuminuria & 11 & 100 \\
Glomerular hematuria & 8 & 73 \\
\hline${ }^{\text {a Modification of Diet in Renal Disease }}$ & & \\
${ }^{\mathrm{b}}$ Chronic Kidney Disease Epidemiology Collaboration & &
\end{tabular}

Our review shows that the majority of CPGs focused on the early diagnosis of the CKD are of good quality and developed by organizations that develop CPGs. The recommended CPGs have a medium to high score in all the domains. The CPGs recommended with modifications only have a medium to high score on scope and purpose, rigor of development and clarity of presentation domains. However, the domains on the stakeholder involvement, applicability and editorial independence did not reach a score of medium category.

\section{Comparison with the existing literature}

In general, all CPGs have their lowest averages in the stakeholder involvement, applicability and editorial independence domains, which could partly explain why the incidence of the CKD hasn't decreased [3]. In the review by López-Vargas et al., regarding the CPGs published between 2002 and 2011, similar results have been found [6]. The domains with the lowest average were stakeholder involvement, applicability, and editorial independence. The review of Sekercioglu et al., regarding CPGs published between 2003 and 2015 that focused in the alterations in the bone mineral metabolism in CKD, reported as well that the domains with the lowest averages (all being in the category very low) were stakeholder involvement, applicability, and editorial independence [7]. Our results are similar to those found by Gagliardi and Brouwers; they analyzed systematic reviews regarding different pathologies, which included CPGs published since 2008, finding that the three domains with the lowest scores were stakeholder involvement, applicability, and editorial independence. Among the factors associated with the applicability, there was a significantly higher average in the CPGs elaborated by groups that develop CPGs. Unlike our study, they found a significantly higher average in the CPGs that were published between 2010 and 2012. In their conclusions, they state that the applicability of the CPGs has not increased in relation to the those published before 2008 and that the cost to elaborate CPGs is not being rewarded by their applicability [24].

\section{Strategies for implementation the CPGs}

The findings of our review and those of others point to the same weakness in the current CPGs. Due to the 
weaknesses in the implementation, the recommendations with the best evidence are not being used fully in the daily practice. This, as we mentioned before, can be one of the determining factors in the increasing incidence of CKD, despite the existing recommendations in the CPGs regarding prevention. To enhance the applicability of the CPGs, it has been recommended, among other strategies, to endow clinics with instruments that facilitate the implementation of these CPGs. The idea is to simplify the recommendations to be executed and to achieve the facilitation of the application and understanding of the patients and the healthcare providers $[25,26]$. In a recent study, all ideal characteristics for a CPGs' implementation instrument were explored, and identified 12 items. Among these items, the following were highlighted: identification of target users; involvement of target users were in the tool development; and conduction of pilot-test of the tool in target users [27]. Kastner et al. found that the factors associated with the implementation of the CPGs are the ones related to the creation of the content of the CPG and the proper communication of its content [28]. In relation to the content, they consider the stakeholder involvement and the feasibility important among others, similarly to our study. Another study was executed to develop a model based in the evidence for the implementation of the CPGs of clinical practice. Based on their results, the GUIDE-M (Guideline Implementability Decision Excellence Model) was created with the purpose of helping organizations that developed CPGs to create CPGs with recommendations easier to implement, facilitate the users' adoption and to motivate researchers for deeper investigations in the topic [29].

On the other hand, the AGREE II instrument has been used more as an instrument for assessing CPGs' quality despite the fact that it was also created to help achieve the requirements of the development and presentation of the CPGs. In our study, we reported that only $23.1 \%(3 / 13)$ of the CPGs, performed a process of self-assessment or compliance verification of the requisites needed for the development of the CPG, hence this could have influence the low scores of the stakeholder involvement and applicability domains. In 2016 the AGREE Reporting Checklist was published, which seeks, among its objectives, to help the CPGs' developers take into account each of the quality requirements proposed in AGREE II [30]; with the use of this instrument, it would be possible in future CPGs to overcome the weaknesses found in our study and in the other ones aforementioned. Within the AGREE platform, a research project is registered to create a new instrument that complements AGREE II, which has been named AGREE-REX (Appraisal of CPGs REsearch and Evaluation - Recommendations EXcellence) [31]. The purpose of this project is to create an instrument that is useful for the development, report and evaluation activities related to the credibility, optimization, reliability and implementability of the CPGs recommendations. It is expected to be ready for publication in the following years.

\section{Implications for clinical practice}

The general recommendation especially in low- and middle-incomes countries, is the adaptation of high quality CPGs to their context by using recommendations based in the best evidence available and focused in the early diagnosis of the CKD [32]. Ours results allow the endorsement of the CPGs developed in Scotland, Malaysia, Australasia and the United Kingdom (NICE guideline) to support other developer groups to create their own CPGs or adapt them to their context. For this last purpose, the CPG from the USA is not endorsed due to a low and very low score on the stakeholder involvement and applicability domains, respectively.

We considered that the adapted CPGs from Mexico, Argentina, Chile, Italy and SLANH have recommendations of utility in their context but they require an improvement in the domains stakeholder involvement and applicability in future updates so they can truly contribute to make an impact over the incidence of the CKD.

\section{Strengths and weaknesses}

As far as we know, our study represents the first analysis published on CPGs quality over the last 8 years worldwide, with no restriction regarding language, focused on the early diagnosis of the CKD including recommendations based on the latest evidence. Among the strengths, we included a systematic search of the published CPGs, a high degree of agreement among reviewers, a great expertise of methodological experts in the evaluation of CPGs using the AGREE II instrument. Additionally, two of the reviewers are specialists in the area of nephrology. We highlight as a strength the fact that the nephrologist reviewers work in different continents and are native from different countries.

Among the weaknesses, we mentioned that our inclusion criteria only admitted potentially high quality CPGs, which can be a selection bias. Although no quality threshold has been established in the AGREE II instrument, we accepted as satisfactory an average score of $60 \%$ or more in the domains, which may be argued by other authors.

\section{Conclusions}

The majority of the CPGs focused on the early diagnosis of the CKD are recommended for their use in clinical practice. However, in clinical practice we notice an increase in incidence of CKD, which suggests that the recommendations probably are not being properly 
applied. We found that the AGREE II domains with the lowest average in all CPGs are the stakeholder involvement and the applicability, which may be factors influencing implementation. The cost to elaborate CPGs is not being rewarded by their implementation, for this reason, the general recommendation especially in lowand middle-incomes countries, is the adaptation of high quality CPGs to their context.

\section{Additional file}

Additional file 1: Summary of the excluded guidelines and exclusion criteria. We reported the titles of the guidelines that were excluded and the inclusion criteria they failed to meet. (DOCX $19 \mathrm{~kb}$ )

\section{Abbreviations}

AGREE: Appraisal of Guidelines for Research \& Evaluation; CKD: Chronic kidney disease; CPG: Clinical practice guideline; NICE: National Institute for Health and Care Excellence

\section{Acknowledgements}

The authors thank Pablo Alonso-Coello, Iberoamerican Cochrane Centre, for his support in the literature search and his thoughtful comments.

\section{Funding}

No sources of support supplied.

\section{Availability of data and materials}

The datasets used and/or analyzed during the current study are available from the corresponding author on reasonable request.

\section{Authors' contributions}

JC, GU conceptualized the study. JC, RV, KS, DO analyzed the data. JC, RV, DO, GU contributed to interpretation and manuscript preparation. All authors read and approved the final manuscript.

\section{Authors' information}

$\mathrm{JC}$ is a physician specialized in Internal Medicine and Nephrology, with a Master degree in Clinical Epidemiology. He is a teacher in the Faculty of Medicine of the Universidad de Cartagena, Colombia and leader of the Alta Tension research group; also, is a PhD candidate in Methodology of Biomedical Research, Universidad Autónoma de Barcelona, Spain.

\section{Ethics approval and consent to participate}

Not applicable.

\section{Consent for publication}

Not applicable.

\section{Competing interests}

The authors declare they have no competing interests.

\section{Publisher's Note}

Springer Nature remains neutral with regard to jurisdictional claims in published maps and institutional affiliations.

\footnotetext{
Author details

${ }^{1}$ Facultad de Medicina, Universidad de Cartagena, Cartagena 130014 Colombia. ${ }^{2}$ Nefrologia y Diálisis SAS, Cartagena 130001, Colombia. ${ }^{3}$ Iberoamerican Cochrane Centre, 08041 Barcelona, Spain. ${ }^{4}$ Biomedical Research Institute Sant Pau, 08025 Barcelona, Spain. ${ }^{5}$ Hospital de la Santa Creu i Sant Pau, 08041 Barcelona, Spain. 'University Hospital Vall d'Hebron, 08035 Barcelona, Spain. ${ }^{7}$ CIBER Epidemiología y Salud Pública (CIBERESP), Barcelona, Spain
}

Received: 30 August 2017 Accepted: 15 May 2019

Published online: 28 May 2019

\section{References}

1. Schoolwerth A, Engelgau M, Hostetter T. A public health action plan is needed for chronic kidney disease. Adv Chronic Kidney Dis. 2005;12:418-23.

2. Levey AS, Andreoli SP, DuBose T, Provenzano R, Collins AJ. CKD: common, harmful, and treatable-world kidney day 2007. Am J Kidney Dis. 2007:49:175-9.

3. United States Renal Data System. 2016 USRDS annual data report: Epidemiology of kidney disease in the United States. Bethesda: National Institutes of Health, National Institute of Diabetes and Digestive and Kidney Diseases; 2016. https://www.usrds.org/2016/view. Accessed 19 Sept 2016

4. AGREE Collaboration. Development and validation of an international appraisal instrument for assessing the quality of clinical practice guidelines: the AGREE project. Qual Saf Health Care. 2003;12:18-23.

5. Brouwers MC, Kho ME, Browman GP, Burgers JS, Cluzeau F, Feder G, et al. AGREE II: advancing guideline development, reporting and evaluation in health care. CMAJ. 2010;182:E839-42.

6. López-Vargas P, Tong A, Sureshkumar P, Johnson D, Craig J. Prevention, detection and management of early chronic kidney disease: a systematic review of clinical practice guidelines. Nephrology. 2013;18:592-604.

7. Sekercioglu N, Al-Khalifah R, Ewusie J, Elias R, Thabane L, Busse J, et al. A critical appraisal of chronic kidney disease mineral and bone disorders clinical practice guidelines using the AGREE II instrument. Int Urol Nephrol. 2017:49:273-84.

8. Alonso-Coello P, Irfan A, Sola I, Gich I, Delgado-Noguera M, Rigau D, et al. The quality of clinical practice guidelines over the last two decades: a systematic review of guidelines appraisal studies. Qual Saf Health Care. 2010;19:e58. https://doi.org/10.1136/qshc.2010.042077.

9. Arévalo-Rodríguez I, Pedraza O, Rodríguez A, Sánchez E, Gich I, Solá I, et al. Alzheimer's disease dementia Guidelines for diagnostic testing: a systematic review. Am J Alzheimers Dis Other Dement. 2013:28:111-9.

10. Chen $Y$, Hu S, Wu L, Fang $X, X u$ W, Shen G. Clinical practice guidelines for hypertension in China: a systematic review of the methodological quality. BMJ Open. 2015. https://doi.org/10.1136/bmjopen-2015-008099.

11. Diagnosis and Management of Chronic Kidney Disease: a National Clinical Guideline. https://www.sign.ac.uk/archived-guidelines.html. Accessed 19 May 2015.

12. Alcázar R, Egocheaga Ml, Orte L, et al. Documento de consenso SENsemFYC sobre la enfermedad renal crónica [SEN-SEMFYC consensus document on chronic kidney disease]. Nefrología. 2008;28:273-82 PMID: 18590493

13. Rensma PL, Hagen EC, van Bommel EFH et al. Richtlijn voor de behandeling van patiënten met Chronische Nierschade [directive for the treatment of patients with chronic kidney damage]. http://docplayer.nl/629519-Richtlijnvoor-de-behandeling-van-patienten-met-chronische-nierschade-cns.html. Accessed 18 May 2015.

14. Guía de práctica clínica. Prevención, diagnóstico y tratamiento de la enfermedad renal crónica temprana [clinical practice guideline. Prevention, diagnosis and treatment of early chronic kidney disease]. http://www. cenetec.salud.gob.mx/descargas/gpc/CatalogoMaestro/335_IMSS_09 Enfermedad_Renal_Cronica_Temprana/EyR_IMSS_335_09.pdf. Accessed 18 May 2015.

15. Guía de práctica clínica sobre prevención y detección precoz de la enfermedad renal crónica en adultos en el primer nivel de atención. [Clinical practice guideline on prevention and early detection of chronic kidney disease in adults in the first level of care]. https://www.argentina. gob.ar/salud/calidadatencionmedica/guiaspracticaclinica. Accessed 25 May 2015.

16. Guía clínica. Prevención de enfermedad renal crónica [Clinical Guide. Prevention of chronic kidney disease]. http://diprece.minsal.cl/leinformamos/auge/acceso-guias-clinicas/. Accessed 25 May 2015.

17. Clinical Practice Guidelines. Management of chronic kidney disease in adults. Malaysia; 2011. http://www.msn.org.my. Accessed 20 June 2015

18. MacGregor MS, Taal MW. Renal association clinical practice guideline on detection, monitoring and management of patients with CKD. Nephron Clin Pract. 2011;118(S1):C71-100.

19. Identificazione, prevenzione e gestione della malattia renale crónica nell'adulto [Identification, prevention and management of chronic kidney 
disease in adults]. http://documenti.sinitaly.org/malattia-renale-cronica. Accessed 25 May 2015.

20. Guías Latinoamericanas de Practica Clínica Sobre la Prevención Diagnostico y Tratamiento de los Estados 1-5 de la Enfermedad Renal Crónica [Latin American Guidelines on Clinical Practice on the Prevention and Diagnosis of Chronic Kidney Disease 1-5]. http://www.slanh.net/? $=1471$. Accessed 21 June 2015.

21. KHA-CARI Guidelines: Chronic Kidney Disease. http://www.cari.org.au. Accessed 25 May 2015.

22. ScreeningMonitoring, and treatment of stage 1 to 3 chronic kidney disease: a clinical practice guideline from the American College of Physicians. Ann Inter Med. 2013;159:835-47. https://doi.org/10.7326/0003-4819-159-12201312170-00726

23. Chronic kidney disease in adults: assessment and management. https://www.nice.org.uk/quidance/cg182. Accessed 20 June 2015

24. Gagliardi A, Brouwers M. Do guidelines offer implementation advice to target users? A systematic review of guideline applicability. BMJ Open. 2015. https://doi.org/10.1136/bmjopen-2014-007047.

25. Patel V, Arocha J, Diermeier M, Greenes R, Shortliffe E. Methods of cognitive analysis to support the design and evaluation of biomedical systems. J Biomed Inform. 2001;34:52-66.

26. Gagliardi A, Brouwers M, Palda V, Lemieux-Charles L, Grimshaw J. How can we improve guideline use? A conceptual framework of implementability. Implement Sci. 2011;6:26.

27. Gagliardi A, Brouwers M, Bhattacharyya O, et al. A framework of the desirable features of quideline implementation tools (Gltools): Delphi survey and assessment of Gltools. Implement Sci. 2014;9:98.

28. Kastner M, Bhattacharyya O, Hayden L, et al. Guideline uptake is influenced by six implementability domains for creating and communicating guidelines: a realist review. J Clin Epidemiol. 2015;68(5):498-509.

29. Brouwers M, Makarski J, Kastner M, et al. The guideline Implementability decision Excellence model (GUIDE-M): a mixed methods approach to create an international resource to advance the practice guideline field. Implement Sci. 2015;10:36.

30. Brouwers MC, Kerkvliet K, Spithoff K. AGREE next steps consortium. The AGREE reporting checklist: a tool to improve reporting of clinical practice guidelines. BMJ. 2016. https://doi.org/10.1136/bmj.i4852.

31. AGREE: Innovations to enhance the capacity of practice guidelines to improve health and health care systems: Recommendation EXcellence (AGREE-REX). https://www.agreetrust.org/resource-centre/agree-rexrecommendation-excellence/. Accessed 6 June 2016.

32. Jha V, Arici M, Collins AJ, et al. Understanding kidney care needs and implementation strategies in low- and middle-income countries: conclusions from a "kidney disease: improving global outcomes" (KDIGO) controversies conference. Kidney Int. 2016;90(6):1164-74.

Ready to submit your research? Choose BMC and benefit from:

- fast, convenient online submission

- thorough peer review by experienced researchers in your field

- rapid publication on acceptance

- support for research data, including large and complex data types

- gold Open Access which fosters wider collaboration and increased citations

- maximum visibility for your research: over $100 \mathrm{M}$ website views per year

At $\mathrm{BMC}$, research is always in progress.

Learn more biomedcentral.com/submissions 